\title{
8
}
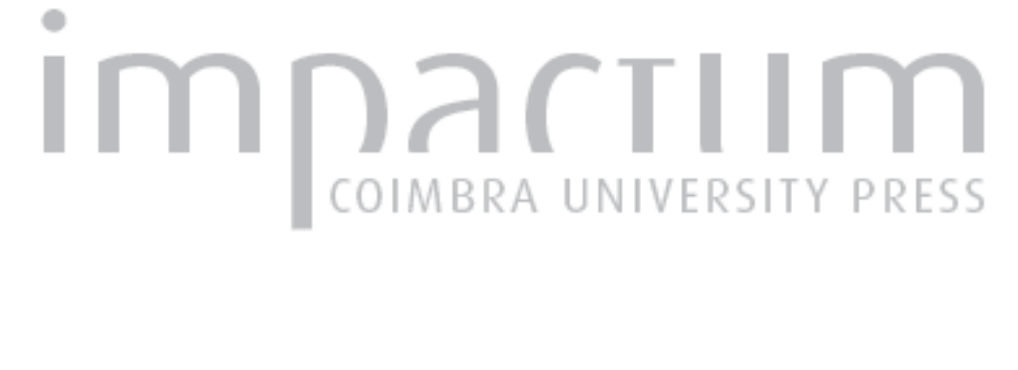

\section{Cidadãos europeus ou uma Europa dos cidadãos?}

\section{Autor(es): Rio, Olinda Martinho}
Publicado por: Centro de Informação Europe Direct de Aveiro; Centro de Estudos Interdisciplinares do Século XX

URL

persistente:

URI:http://hdl.handle.net/10316.2/33977

DOI:

DOI:http://dx.doi.org/10.14195/1647-6336_11_6

Accessed : $\quad$ 26-Apr-2023 16:00:01

A navegação consulta e descarregamento dos títulos inseridos nas Bibliotecas Digitais UC Digitalis, UC Pombalina e UC Impactum, pressupõem a aceitação plena e sem reservas dos Termos e Condições de Uso destas Bibliotecas Digitais, disponíveis em https://digitalis.uc.pt/pt-pt/termos.

Conforme exposto nos referidos Termos e Condições de Uso, o descarregamento de títulos de acesso restrito requer uma licença válida de autorização devendo o utilizador aceder ao(s) documento(s) a partir de um endereço de IP da instituição detentora da supramencionada licença.

Ao utilizador é apenas permitido o descarregamento para uso pessoal, pelo que o emprego do(s) título(s) descarregado(s) para outro fim, designadamente comercial, carece de autorização do respetivo autor ou editor da obra.

Na medida em que todas as obras da UC Digitalis se encontram protegidas pelo Código do Direito de Autor e Direitos Conexos e demais legislação aplicável, toda a cópia, parcial ou total, deste documento, nos casos em que é legalmente admitida, deverá conter ou fazer-se acompanhar por este aviso.

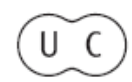


DEBATER

A EUROPA

jul-dez 2014

QUE EUROPA(S)?

CONTEXTOS E DESAFIOS 


\title{
Cidadãos europeus ou uma Europa dos cidadãos?
}

\author{
Olinda Martinho Rio \\ Doutoranda FLUC \\ E-mail: ommrio@hotmail.com
}

\section{Resumo}

Compreender, interiorizar e exercer a Cidadania Europeia em todo o seu potencial alcance passa por um alargado e permanente debate que, com esta apresentação, pretendemos alimentar. Se, por um lado, constatamos a validade intemporal das bases fundacionais da atual União Europeia, enquanto espaço convergente, aglutinador de diferenças que se complementam e de marcas que expressam um passado construído e enraizado, com um futuro comum em perspetiva, verificamos, por outro, a distância (por vezes profunda e em crescendo, ao longo dos últimos anos) que existe entre as cidadãs e cidadãos europeus, cujos reflexos se afiguram incontornáveis ao nível económico, social e cultural. A noção de Cidadania está historicamente ligada à ideia de pertença nacional. Ao mesmo tempo, é precisamente a nacionalidade de um Estado Membro que, do ponto de vista jurídico, confere a Cidadania Europeia (que não substitui, mas antes complementa a cidadania nacional). O passo principal está dado. Falta agora fazer emergir um verdadeiro sentimento de pertença a um espaço público comum - o europeu -, e encontrar mecanismos para dotar o cidadão europeu de direitos e responsabilidades políticos e sociais que vão para além dos que prevalecem por partilharmos um "mercado comum". Tal intento significa construir uma "comunidade de afetos", valorizando a dimensão afetiva e não só a dimensão mercantilista da Comunidade Europeia. Vai ser a maturidade crescente da Cidadania da União Europeia, entendida como a dinâmica e o suporte para uma genuína identidade social e cultural da União Europeia, que vai permitir dar passos no sentido das expectativas criadas aos europeus rumo a uma desejada integração civil e política muito mais abrangente e inspiradora do que algo que decorre apenas da integração económica. Uma CE coerente e consequente e menos permeável à oscilação de fatores de ordem económico-financeira. 
Palavras-chave: Cidadania; evolução; dimensão identitária; dimensão política; dimensão social

\begin{abstract}
To understand, internalize and pursue European Citizenship in their potential range, undergoes an extensive and ongoing debate that with this presentation, we intend to cherish. If on the one hand, we see the timeless validity of the foundational basis for the current European Union, while a convergent space unifying the differences that complement and of brands expressing a past rooted and built with a common future in perspective, we find, on the other hand, the distance (sometimes deep and growing over the last few years ) that exists between citizens and European citizens, whose reflexes seem insurmountable at economic, social and cultural level . The notion of citizenship is historically linked to the idea of national belonging. At the same time, it is precisely the nationality of a Member State, that from the legal point of view, gives the European Citizenship concept (it does not replace, but rather complements the national citizenship). The main step is taken. Now, they need to bring out a real sense of belonging to a common public space - the European - and find mechanisms to provide the European citizen of political and social rights and responsibilities that go beyond those that prevail due to the fact that we share a "common market ". This means an attempt to build a "community of affections", valuing the affective dimension and not only the mercantile dimension of the European Community . It will be the growing maturity of EU citizenship, understood as the dynamics and support for genuine social and cultural identity of the European Union, that will allow to move towards the expectations created to the Europeans towards a desired civil and political integration, more comprehensive and inspiring than something that just stems from an economic integration. A coherent EC and consequently less permeable to the oscillation of economic and financial factors.
\end{abstract}

Keywords: Citizenship; evolution; identity dimension; political dimension; social dimension

Compreender, interiorizar e exercer a Cidadania Europeia em todo o seu potencial alcance passa por um alargado e permanente debate que, com esta apresentação, pretendemos alimentar.

Se, por um lado, constatamos a validade intemporal das bases fundacionais da atual União Europeia, enquanto espaço convergente, aglutinador de diferenças que se complementam e de marcas que expressam um passado construído e enraizado, com um 
futuro comum em perspetiva, verificamos, por outro, a distância - por vezes profunda e em crescendo, ao longo dos últimos anos - que existe entre as cidadãs e cidadãos europeus, cujos reflexos se afiguram incontornáveis ao nível económico, social e cultural.

A noção de Cidadania está historicamente ligada à ideia de pertença nacional. Ao mesmo tempo, é precisamente a nacionalidade de um Estado Membro que, do ponto de vista jurídico, confere a Cidadania Europeia (que não substitui, mas antes complementa a cidadania nacional). O passo principal está dado. Falta agora fazer emergir um verdadeiro sentimento de pertença a um espaço público comum - o europeu -, e encontrar mecanismos para dotar o cidadão europeu de direitos e responsabilidades políticos e sociais que vão para além dos que prevalecem por partilharmos um "mercado comum". Tal intento significa construir uma "comunidade de afetos", valorizando a dimensão emocional e não só a dimensão mercantilista da Comunidade Europeia. Vai ser a maturidade crescente da Cidadania da União Europeia, entendida como a dinâmica e o suporte para uma genuína identidade social e cultural da União Europeia, que vai permitir dar passos no sentido das expectativas criadas aos europeus rumo a uma desejada integração civil e política muito mais abrangente e inspiradora do que algo que decorre apenas da integração económica. Uma Cidadania Europeia coerente e consequente e menos permeável à oscilação de fatores de ordem económico-financeira.

\section{I - A síndrome da "pós-democracia"}

A cultura de participação é o primeiro passo para consolidar uma democracia capaz de garantir os direitos sociais de todos os cidadãos. Para que esta participação se concretize, terão que existir mecanismos de envolvimento que os levem a apostar na sua participação cívica. E a democracia não se refere só à ordem do poder político do Estado-Nação ou das Organizações Internacionais. Começa na relação interindividual, passa pela família, pelas relações económicas, políticas e culturais.

A síndrome da "pós-democracia", como lhe chama o iluminado e inspirador Jürgen Habermas, é um fenómeno de transformação da democracia que atualmente enfrentamos, 
na Europa em geral e em Portugal em particular, que se prende: com a quebra de participação eleitoral e da militância partidária, com uma apatia e alienação política generalizadas, contrabalançada, de alguma forma, por minorias ativas e grupos de protesto que reclamam uma democracia mais direta. Esta situação, de distanciamento crescente entre os cidadãos e o sistema político, transversal a quase todos os países europeus, pode ser explicada, ainda segundo Habermas, como a resposta racional dos cidadãos à perceção do esmorecimento das suas oportunidades de terem algum impacto sobre a verdadeira orientação da política governamental e pela redução da confiança na competência dos partidos políticos. Este ceticismo em relação à democracia aumenta com o crescimento da desigualdade social. Quanto mais forte é o sentimento de falta de resposta, de não estarem a ser tidos em conta os interesses dos votantes, sobretudo nas classes mais desfavorecidas, maior é a indiferença em relação ao sistema político vigente.

$\mathrm{O}$ poder decrescente dos governos nacionais para formularem as condições económicas e sociais e resolverem grandes problemas é hoje uma realidade factual. Os governos nacionais sofrem de um espaço limitado para a ação política porque a mudança global de mercados, em especial os mercados financeiros, estão fora do alcance da regulação nacional. "Nesta sociedade mundial, altamente interdependente, até as superpotências estão a perder a sua autonomia funcional em campos importantes da política"1. Aquele Estado que vivia dos impostos e tinha como obrigação um retorno como Estado-Providência acabou. "Os Estados-nação terão de romper com a imagem obsoleta que fazem de si mesmos, segundo a qual gozam de soberania e são livres de tomar decisões de política orçamental, social e económica sem atenderem aos efeitos colaterais que advêm da globalização"2 e, no nosso caso, de sermos Estados membros da EU, pois “ as decisões democráticas de um Estado não podem ignorar os interesses de outros Estados, que sofrerão as consequências dessas mesmas decisões numa União Monetária" ${ }^{3}$.

Também por isso a realização regular de eleições nacionais já não entusiasma. Esta "ficção de soberania nacional" impede que os países vistos como " doadores" aceitem uma solidariedade a curto prazo - que prejudicaria a sua situação imediata perante o eleitorado -

\footnotetext{
${ }^{1}$ HABERMAS, Jürgen (2014).

${ }^{2}$ Idem.

${ }^{3}$ POIARES MADURO, Miguel (2014).
} 
para com os países vistos como "recetores" ao nível de transferências transfronteiriças economicamente necessárias, que defenderiam o seu próprio interesse no longo prazo, ou seja, " a libertação das garras dos mercados financeiros e o pedir contas aos investidores em vez de aos contribuintes" ${ }^{\prime}$, garantindo assim os interesses democráticos das gerações futuras.

“...democratic malfunction in national political processes,... justify an active EU role. Instances where the pressing needs of today's electoral cycles may lead the political actors to make short-term decisions without fully considering future consequences.

Notably, the control exercised by EU law on national public debt and budget deficits can be seen, among other things, as correcting a problem of intergenerational democracy. The freedom to do things that the current members of the political community acquire by incurring on large budget deficits may limit the democratic freedom of deliberation for future generations. Miguel Poiares Maduro ( 2010) ${ }^{5}$

A alternativa, a meu ver, está na "transnacionalização da democracia", no alargar da cadeia de legitimação democrática para lá das fronteiras do Estado-nação, na criação de um novo tipo de comunidade política supranacional. Uma sociedade mundial constituída politicamente como já defendiam Kant, Jacques Maritain e agora Habermas: "uma institucionalização das decisões comuns que seja insuspeita do ponto de vista democrático". A tendência para a internacionalização da democracia e da política não é nova, teve início com a criação da ONU e da sua política de direitos humanos e com o desenvolvimento do Direito Internacional após a segunda Grande Guerra. Seria desejável que não fosse necessária mais nenhuma catástrofe para prosseguir neste caminho.

A União Europeia, com as suas virtudes e os seus defeitos, é um exemplo muito completo, e já levado à prática, de como uma comunidade deste tipo pode ser constituída. Neste momento, os desequilíbrios estruturais entre economias nacionais dentro da zona euro e até fora dela vão forçar os Estados-membros da EU a darem passos rumo à integração política. A questão é consensual e "não se trata de saber se devemos, mas sim

\footnotetext{
4 HABERMASS, Jürgen (2014).

${ }^{5}$ MADURO, Miguel Poiares (2010).
} 
como devemos dar passos rumo a uma união política que permita a legitimação de políticas conjuntas e harmonizadas"

Os partidos que defendem uma forma de tecnocracia que "consolida" os Estadosmembros individuais e os "talha segundo o modelo de democracias conformadas aos mercados" são obsoletos, os radicais nacionalistas são perigosos. O sistema político tem de ser reinventado por aqueles que percebem na atual crise um desafio de dimensões históricas para proceder à mudança de paradigma para a política na EU e fazer a diferença.

"It requires political leathership to make this crisis a source of energy rather than paralysis. This is a time not for conservatism but for re-invention"7

\section{II - Um povo e um espaço público europeus dignos desse nome}

O debate atual sobre a EU restringe-se às saídas imediatas da crise bancária, monetária e da dívida, perdendo de vista a dimensão política e a força civilizadora de uma Europa forte e coesa. Esta redução à perspetiva economicista oculta um diagnóstico mais profundo que os entendidos definem como: a falta de competências da União Europeia para a harmonização das economias nacionais e o erro da construção de uma união monetária sem as necessárias capacidades políticas de controlo a nível europeu. A existência desta união monetária, faria supor, nomeadamente, a existência de um "governo económico" na zona euro e a respetiva parlamentarização da política financeira que evitasse $o$ empoderamento tecnocrático a que assistimos e que assegurasse o Pacto de Estabilidade, hoje, tão esvaziado. Mas, não é assim. O Conselho Europeu, liderado pela Alemanha, sublinha como prioridade que cada Estado individual equilibre, por si só, o seu orçamento nacional desvalorizando um projeto cooperativo, europeu, que promova o crescimento e a competitividade da zona euro como um todo. Face a uma desafio de dimensões históricas, mantem-se a retórica de países doadores e países recetores evitando a questão de saber, sobretudo a Alemanha, quem deve, afinal, a quem, e reconhecer o que, ainda nas palavras de Habermas, será o seu destino partilhado para lá das fronteiras nacionais, continuando a valorizar as questões de distribuição (quem fica com o quê) em detrimento de questões

\footnotetext{
${ }^{6}$ HABERMASS, Jürgen (2013).

${ }^{7}$ LEONARD, Mark (2014).
} 
identitárias (quem somos) ${ }^{8}$. Apesar de tudo, o caminho para uma Europa capaz de agir politicamente e legitimada democraticamente não está bloqueado. O desafio está em conseguir equilibrar os imperativos dos mercados e a força reguladora da política. $\mathrm{O}$ Tratado de Lisboa já representa o troço mais longo do caminho. Agora, uma União Política implica a existência de um demos, um povo europeu, e de um ethos ou seja um espaço público europeu digno desse nome ${ }^{9}$; uma identidade europeia, de tipo diferente, baseada nos direitos decorrentes da Cidadania Europeia e na partilha de valores culturais e políticos comuns.

\section{III - Uma Europa que coloque as pessoas no centro da agenda política}

As eleições para o Parlamento Europeu são sempre marcadas por uma elevada abstenção e um grande desinteresse. Só duas vezes a abstenção nas europeias ficou abaixo dos 50\%. Em Portugal, nas primeiras eleições para o Parlamento Europeu, em 1987, apenas $27,5 \%$ dos eleitores não foram votar. Nas seguintes, dois anos depois, a abstenção subiu para os $48 \%$. A partir daí disparou para os $60 \%$ e não voltou a descer. A falta de empenhamento cívico advém, talvez, do desconhecimento dos direitos associados ao estatuto de cidadãos da União Europeia, apesar do impacto direto destes no quotidiano de todas e todos nós. Apercebemo-nos do direito de circular e residir livremente no território da $\mathrm{EU}$, pois é aquele que tem um impacto mais direto nas nossas vidas. Contudo é de indagar: é conhecido que existe uma Carta de Direitos dos Cidadãos Europeus? Sabemos que temos direitos quando efetuamos uma compra fora de Portugal? Ou que temos direito a proteção se estivermos num país onde Portugal não tem representação diplomática ou consular? Ou que podemos votar para as eleições locais de qualquer município europeu quando aí residimos? Ou, ainda, que existe uma iniciativa recente, " a iniciativa cidadã”, que permite que um conjunto de cidadãos apele diretamente à Comissão Europeia?

A noção de Cidadania está historicamente ligada à ideia de pertença nacional. Ao mesmo tempo, é precisamente a nacionalidade de um Estado Membro que, do ponto de vista jurídico, confere a Cidadania Europeia - que não substitui, mas complementa a

\footnotetext{
${ }^{8}$ HABERMASS, Jürgen (2013).

${ }^{9}$ POIARES MADURO, Miguel (2010).
} 
cidadania nacional. O passo principal está dado. Falta agora fazer emergir um verdadeiro sentimento de pertença a um espaço público comum - o europeu - e encontrar mecanismos para conferir ao cidadão europeu direitos e responsabilidades políticos e sociais que vão para além dos que prevalecem por partilharmos um "mercado comum”. Falta construir uma “comunidade de afetos"10, valorizando a dimensão emocional e social e não só a dimensão mercantilista da Comunidade Europeia. Vai ser a maturidade crescente da Cidadania Europeia (CE) como instituição que vai majorar a integração política e conduzir a um crescendo da identificação com a UE. Mais de meio bilião de europeus, possuindo a nacionalidade de um dos 28 Estados Membros (EM), são Cidadãos Europeus. A nacionalidade de um EM e a CE já não podem ser percecionadas em separado. Somos, de facto, portugueses-europeus ${ }^{11}$. A Cidadania supranacional, europeia, que vai para além do Estado-Nação, está para ficar. Já não é apenas um estatuto legal atribuído aos nacionais dos EM. A CE influencia a perceção de identidade e de cultura dos nacionais destes EM. Influencia em inúmeros aspetos vitais dos EM, desempenha um papel pivô na jurisprudência do Tribunal de Justiça Europeu (ECJ), molda as fronteiras entre a legislação nacional e a legislação europeia ${ }^{12}$. O seu potencial vai, pois, muito para além das evasivas formulações que aparecem nos Tratados. É a retaguarda de uma importante, mas pouco debatida e pouco estudada, transformação em curso: " uma Europa que coloque as pessoas no centro da agenda política”. Este foi, afinal, o mote do ano Europeu dos Cidadãos em 2013.

\section{IV - “A UE e a Promessa de Democracia: Como podem a Educação para a Cidadania e}

\section{a Sociedade Civil contribuir?"}

Fui recentemente relatora da Conferência NECE-2013" "The EU and the Promise of Democracy: What can Citizenship Education and Civil Society contribute?" na Holanda,

\footnotetext{
${ }^{10}$ Apud Adriano Moreira, no discurso “ O Futuro de Portugal”, proferido no ISCAC, em Coimbra.

11 Soares, Mário (2001).

${ }^{12}$ Poiares Maduro, Miguel (2010).

13 A NECE - Networking European Citizenship Education é uma iniciativa da Agência Federal Alemã de Educação Cívica e de outros parceiros europeus que tem em vista manter uma rede transnacional de Educação para a Cidadania na Europa. Constitui-se como uma plataforma para
} 
em Haia. Nesta Conferência, a abordagem ao futuro da EU num contexto de Educação para a Cidadania teve um momento de reflexão sobre "Cenários Possíveis para a União Europeia em 2030" que entretanto foi apresentado em várias iniciativas posteriores e tem uma página de debate no site da NECE - Networking European Citizenship Education. Todos sabemos que é impossível prever o futuro. Quem poderia ter previsto a crise económica, a primavera Árabe, as novas formas de cidadania ativa através das redes sociais. Ou, nos últimos 20 anos na EU: a abertura das fronteiras, a união monetária, a instituição da Cidadania Europeia, o alargamento a 28 países, uma Carta de Direitos Europeus. Podemos, no entanto, explorar o futuro, imaginando cenários possíveis. Este exercício de antecipação ajuda as pessoas e as organizações a preparar futuras circunstâncias. As que desejamos e as que não desejamos. Quais os efeitos da desastrosa crise económica que vivemos na coesão política da EU? Qual o impacto do envelhecimento da população em termos de sustentação para o processo democrático? E qual será o efeito do poder crescente das novas formas de participação virtual?

A partir destas tendências e incertezas um número plausível de futuras situações podem ser imaginadas. É importante olhar mais longe, sobretudo no que diz respeito a Educação. A Educação é sobejamente reconhecida como um pilar de Cidadania. É sobretudo através da Educação que formamos consciências, construímos personalidades e preparamos cidadãos. A questão que se coloca é: Como podemos preparar as futuras gerações para lidarem com estas e outras incertezas? Ou melhor ainda, como pode a Educação, nomeadamente a Educação Cívica, ajudar as novas gerações a moldarem o futuro da Europa que desejam? Durante os trabalhos desta Conferência quatro imagens futuras da Europa em 2030 foram apresentadas:

A - "Uma Grande Europa": a EU superou a crise e acrescentou mais integração política , económica e social, nomeadamente foi criada uma União Bancária Europeia, uma

profissionais em cidadania e educação cultural, um fórum que permite que o espectro de partes interessadas envolvidas na educação para a cidadania possa interagir. O principal objetivo da iniciativa é promover a europeização da educação para a cidadania, e contribuir para a criação de um público europeu interessado nesta matéria. Para ajudar a alcançar estes objetivos a NECE facilita os contactos, a cooperação e as sinergias no campo da educação formal e não formal da cidadania. Na sua Conferência Europeia Anual - NECE Conference - reúne profissionais e especialistas da área, académicos, professores, decisores políticos e média. 
União Fiscal e um Orçamento Comum, apesar da saída do Reino Unido após o referendo de Cameron em 2016.

B-“Uma Rede Europeia de Nações”: O poder de Bruxelas é devolvido aos EstadosNação. A EU regride à sua condição de "Mercado Comum", uma associação de livre comércio. Noutras esferas fazem-se escolhas independentes. Os Estados atuam com a flexibilidade de uma rede em vez de "em bloco".

C-“Uma União de Comunidades": Emergem duas esferas: a formal /institucional dos Governos nacionais e europeu e uma larga esfera informal na qual operam Comunidades em rede que envidam esforços em prol da melhoria das condições de trabalho, das pensões, da saúde, da educação, do apoio social, através de uma forte participação da sociedade civil e de instituições filantrópicas.

D-“Uma Primavera Europeia": Grupos de pessoas tomaram as ruas exigindo uma democracia mais direta - "líquida". A tendência de centralização na EU é completamente revertida e as instituições formais são substituídas por plataformas onde lideres carismáticos mobilizam as massas para uma participação em torno de um certo tópico.

Representam um excelente testemunho de que é possível pensar nas coisas com pendor prospetivo, alargando horizontes e ajudando a antecipar e preparar para futuras circuntâncias.

Esta ideia de "cenários" ou de pensamento visionário por antecipação, não é nova. Veja-se o célebre e brilhante artigo "Four Cenarios for the reinvention of Europe", ${ }^{14}$ onde Mark Leonard ${ }^{15}$ analisa um novo quadro para a compreensão da eficiência e legitimidade da Europa e examina os obstáculos políticos e jurídicos para uma solução em diferentes Estados membros, as novas divisões culturais na Europa, e a ascensão de novas forças populistas. Segundo o Diretor da ECFR, "Looming behind the euro crisis is a larger and more fundamental challenge: the near-collapse of the EU's political system" e apresenta

\footnotetext{
${ }^{14}$ Leonard, Mark (2011).

${ }^{15}$ Mark Leonard is co-founder and Director of the European Council on Foreign Relations. He is the author of Why Europe Will Run the 21st Century (2005) and What Does China Think? (2008). His publications for the European Council on Foreign Relations include A Power Audit of EURussia Relations (with Nicu Popescu, 2007) and The Spectre of a Multipolar Europe (with Ivan Krastev et al, 2010).
} 
quatro diferentes cenários, neste caso para resolver a crise do euro sem agravar a crise habitual do declínio de poder europeu.

1. Uma integração assimétrica que continuaria a encontrar soluções suplementares, sem alterações ao Tratado de Lisboa. Esta é a solução mais fácil, mas corre o risco de não conseguir resolver a crise, agravando a resistência dos cidadãos da Europa, e mudando de uma UE baseada em regras para uma UE com base em poder tecnocrático.

2. Uma zona euro mais reduzida, desistindo dos gregos e talvez outros, seria mais sustentável e menos dolorosa, mas poderia desencadear um tsunami de pânico que poderia resultar no desmoronamento do euro, uma recessão profunda e uma perda de influência da UE no mundo.

3. Uma União política através da mudança do Tratado para uma Constituição seria o mais completo e durável, mas comporta o risco de fracasso espetacular, por exemplo, através de rejeição por referendo ou dos parlamentos, como já aconteceu no passado, levando à desintegração da própria União Europeia.

4. Federalismo sem os federalistas, em torno de uma maior integração na zona euro fora do âmbito dos tratados e Instituições de UE existentes. Mas esta correria o risco de abertura de um fosso dentro da Europa e a marginalização do núcleo duro EU17.

"The best hope of regaining European credibility, and stemming the tide of disintegration, may be to develop political rather than institutional responses to the anti-European arguments of the populists. The real challenge will be to solve the acute euro crisis without at the same time exacerbating the chronic crisis of declining European power."

Mark Leonard (2011)

Este artigo mereceria uma reflexão mais alargada que sai fora do âmbito deste trabalho sendo esta apenas uma referência que se impõe neste contexto.

\section{Conclusão}

Infelizmente o debate europeu é subvalorizado e a questão europeia mobiliza sobretudo os adversários da União Europeia, seja do processo de integração europeu em 
geral, seja da atual configuração da União. Os sentimentos nacionalistas e populistas crescentes na Europa demonstram a extensão de uma grande incerteza coletiva nas sociedades europeias. Os partidos radicais, de esquerda e de direita, vão aproveitar as eleições europeias - cuja campanha decorre em plena crise ucraniana - para lançar uma clivagem profunda e nada nova entre pró-soviéticos e pró-ocidentais quando pensávamos que a guerra fria tinha terminado, o que pode vir a ser perigoso, potenciar a ascensão de eurocéticos extremistas e um surto de nacionalismo antieuropeu.

Em Portugal, apesar de sermos o país europeu com maior estabilidade das suas fronteiras continentais, praticamente inalteradas desde o século XIII, e com laços profundos com países lusófonos como o Brasil, Angola, Moçambique pela história , pela cultura e pela língua, abraçámos sem medo ser europeus, sem sentir a nossa identidade ou a nossa cultura centenária ameaçadas por aceitarmos o projeto político europeu. " Portugal foi sempre um país entusiasta da integração europeia e onde o ceticismo antieuropeu não teve qualquer sucesso" 16

Como referido por Eduardo Lourenço, muito recentemente, à SIC Notícias, reportando-se à crise económica que atravessamos em Portugal e ao enorme défice democrático decorrente da mesma: "Estamos, no mundo, protegidos por sermos europeus"17. A minha concordância com este ponto de vista é manifesta. É, efetivamente, o que nos tem valido. Hoje, no nosso país, tudo começa a ser perigosamente aceitável, mesmo o que não seria numa democracia de primeira linha que já devíamos ser. Uma justiça célere, uma rede de saúde e de educação sólida e consistente, um sistema de pensões intocável, cenários de insuspeição absoluta sobre percursos académicos, profissionais ou empresariais em políticos com responsabilidades governativas, um registo de paridade em termos de igualdade de género, é o limite mínimo de exigência. É por isso que, como portugueses - europeus, temos uma palavra a dizer sobre o projeto da União Europeia e do que queremos dele. Votar nas próximas eleições europeias de maio de 2014 é o mínimo em relação ao que se espera de cidadãs e cidadãos que refletiram sobre os cenários possíveis num futuro próximo e sabem, portanto, o que querem e o que não querem para si, não permitindo que outros tracem o seu destino.

\footnotetext{
${ }^{16}$ POIARES MADURO, Miguel (2010).

${ }^{17}$ Eduardo Lourenço, em entrevista à SIC Notícias, em outubro de 2013.
} 


\section{Bibliografia}

BUNDESZENTRALE FÜR POLITISCHE BILDUNG/BPB (2013). NECE 2030. Consultado em 10 de jan. 2014. Disponível em https://www.youtube.com/watch?v=BEnXk4JrjII\&feature=player_embedded.

HABERMAS, Jürgen (2012). Um Ensaio sobre a Constituição da Europa. Lisboa: Edições 70.

HABERMAS, Jügen (2013, Outubro). A democracia na Europa de hoje. In Atas da Conferência Internacional de Educação. Lisboa: Fundação Calouste Gulbenkian.

KOCHENOV, Dimitry (2012). The Present and the Future of EU Citizenship: A Bird's Eye View of the Legal Debate. In Jean Monnet Working Paper - NYU School of Law, 02. Consultado em 23 de dez. 2013. Disponível em: http://papers.ssrn.com/sol3/papers.cfm?abstract_id=2063200.

KOSTAKOPOULOU, Dora (2008). The evolution of european union Citizenship. In European Consortium for Political Research - Symposium, 7, 285-295. Consultado em 24 de out. 2013. Disponível em: http://www.palgrave-journals.com/eps/journal/v7/n3/abs/eps200824a.html.

LENAERTS, Koen (2012, October 10). Exploring the limits of the EU Charter of fundamental rights. In European Constitutional Law Review. 8(3), 375-403. Consultado em 18 de out. 2013. Disponível em:

http://journals.cambridge.org/action/displayAbstract?fromPage=online \&aid=8778923.

LEONARD, Mark (2001). Four Cenarios for the reinvention of Europe. Consultado em 15 de abr. 2013. Disponível em: http://www.ecfr.eu/page/-/ECFR43_REINVENTION_OF_EUROPE_ESSAY_AW1.pdf. 
LOURENÇO, Eduardo (1994). A Europa desencantada. Para uma mitologia Europeia. Lisboa: Edições Visão.

MADURO, Miguel Poiares (2006). A constituição plural: constitucionalismo e União Europeia. Cascais: Principia Editora.

MADURO, Miguel Poiares (2010, February). Passion and Reason in European Integration. Palestra apresentada no Forum Constitutionis Europae - Berlim. Consultado em 09 de mar. 2013. Disponível em http://ssrn.com/abstract=1709950.

MADURO, Miguel Poiares (18 de fev. 2014). Discurso como Ministro Adjunto e do Desenvolvimento do Governo de Portugal. Cascais. Consultado em 20 de fev. 2014. Disponível em: http://www.portugal.gov.pt/media/1345932/20140218\%20madr\%20economist.pdf.

MARTINS, Guilherme d'Oliveira (2004). Democracia europeia: a audácia necessária. In Revista "População e Sociedade - CEPESE", 11. Porto: Edições Afrontamento. Consultado em 10 de abr. 2013. Disponível em:

http://www.cepesepublicacoes.pt/portal/obras/populacao-e-sociedade/revista-populacao-esociedade-no-11.

MARTINS, Guilherme W. d'Oliveira (2011). Europa é mais necessária. In FERREIRA, Eduardo P. (Coord.), 25 anos na União Europeia: 125 reflexões (pp. 205-209). Coimbra: Almedina.

MARTINS da Silva, António (2010). História da Unificação Europeia. Coimbra: Imprensa da Universidade.

MARTINS da Silva, António (2013). Sistema Político da União Europeia: Arquitetura, Funcionamento e Teorização. Coimbra: Almedina. 
MOREIRA, Adriano (2013). A Espuma do Tempo - Memórias do Tempo de Vésperas. Coimbra: Almedina.

NECE - Networking European Citizenship Education. Consultado em 11 de abril 2013. Disponível em http://www.bpb.de/veranstaltungen/netzwerke/nece/.

RIBEIRO, Maria Manuela T. (Coord.). (2003). A Europa em Mutação. Cidadania. Identidades. Diversidade Cultural. Coimbra: Quarteto.

RIO, Olinda Martinho (2012, Jan.- Junho). O Tratado de Maastricht e os cidadãos: cidadania ativa em contexto europeu. Revista Debater a Europa - 25 Anos de Integração Europeia de Portugal, 6, pp.114-142. Consultado em 23 de jan. 2014. Disponível em http://www.europe-direct-aveiro.aeva.eu/debatereuropa/.

SOARES, Mário (2001). Português e Europeu. Col. Temas e Debates. Lisboa: Círculo de Leitores.

VALENTE, Isabel M. F; Martins, Ana I. (2009). Vinte Anos de União Europeia: Percepções e Realidades em Portugal. Coimbra: CEIS20.

VALENTE, Isabel M. F. (2013). European Union - Police and Customs cooperation. A historical perspective, Apeiron, Security Dimensions. International \& National Studies, 10(2), 39 - 45.

VILAR, Emílio Rui (2011). 25 Anos de adesão: história de sucesso ou oportunidade perdida? In Ferreira, Eduardo P. (Coord.) (2011). 25 Anos na União Europeia: 125 Reflexões. Coimbra: Almedina. 